\title{
Exploring Depression Symptom References on Facebook among College Freshmen: A Mixed Methods Approach
}

\author{
Megan A. Moreno ${ }^{1,2 *}$, Lauren A. Jelenchick ${ }^{3}$, Rajitha Kota ${ }^{1}$ \\ ${ }^{1}$ Seattle Children's Research Institute, Seattle, USA \\ ${ }^{2}$ Department of Pediatrics, University of Washington, Seattle, USA \\ ${ }^{3}$ University of Minnesota School of Medicine, Minneapolis, USA \\ Email: "megan.moreno@seattlechildrens.org
}

Received March 27 $7^{\text {th }}$,2013; revised May $1^{\text {st }}$, 2013; accepted May $10^{\text {th }}, 2013$

\begin{abstract}
Copyright (c) 2013 Megan A. Moreno et al. This is an open access article distributed under the Creative Commons Attribution License, which permits unrestricted use, distribution, and reproduction in any medium, provided the original work is properly cited.
\end{abstract}

\begin{abstract}
Depression is common among older adolescents and can be challenged to identify. The purpose of this study was to evaluate Facebook displayed depression references and their association with depression and peer perception. First-year college students' Facebook profiles were categorized as Depression Displayers or Non-Displayers. Participants completed a depression screen and were interviewed regarding Facebook displayed depression references. Analyses included logistic regression and qualitative analysis. Among 132 participants (70\% response rate), the average age was 18.4 years (SD 0.49 ) and approximately half were males (48.5\%). Depression Displayers were twice as likely (OR 2.1, 95\% CI: $1.01-4.5, p=0.04$ ) to meet clinical criteria for depression. Qualitative analysis revealed that depression references were viewed as support-seeking or attention-seeking. Displayed depression references were associated with depression; these disclosures may be support-seeking efforts subject to varying interpretations by peers.
\end{abstract}

Keywords: Depression; College Student; Content Analysis; Mixed Methods; Facebook; Social Media

\section{Introduction}

Universities are important settings in which mental health concerns such as depression must be addressed given that approximately half of emerging adults attend post-secondary education (Statistics, 2009). Depression among college students is common and consequential; adverse outcomes include increaseed rates of substance use, co-morbid psychiatric conditions and suicide (Roa, 2006; Garlow et al., 2008; Rao \& Chen, 2009; Deas \& Brown, 2006; Kessler et al., 1995; Hunt \& Eisenberg, 2010; Association A.C.H., 2009; Association A.C.H., 2010). The most common form of depression among emerging adults is major depressive disorder, with a yearly incidence of approximately 8\% (Hunt \& Eisenberg, 2010; Vance, Howe, \& Dellavalle, 2009; Eisenberg, Golberstein, \& Gollust, 2007). Freshman year of college may present increased risks for depression as students have transitioned to an environment that brings new experiences, stressors and uncertainties (Compas et al., 1986; Perry, Hall, \& Ruthig, 2007). The first few months of freshman year are a particularly risky time for feelings of loneliness, depression and social isolation (Cutrona, 1982).

Previous work has suggested that self-disclosure can be a mediator among college students to reduce symptoms of mild depression (Wei, Russell, \& Zakalik, 2005). However, concerns related to stigma regarding mental illness may impede college students' efforts to reach out. Concerns about stigma are associated with less perceived need for help and decreased treatment seeking behavior among college students (Eisenberg et al.,

${ }^{*}$ Corresponding author.
2009). Thus, despite the frequency of depression in this age group, college students struggling with depression symptoms are frequently undiagnosed as many students do not perceive a need for help or do not seek clinical services (Hunt \& Eisenberg, 2010; Eisnberg, Golberstein, \& Gollust, 2007; Zivin et al., 2009). Other barriers to help-seeking particularly among freshmen students include lack of knowledge about available services and privacy concerns (Hunt \& Eisenberg, 2010).

One novel approach towards improving support or resources to college students at risk for depression may be social networking sites (SNSs), such as Facebook and MySpace. These web sites are popular among and consistently used by college students; current data suggests up to $98 \%$ of students maintain a SNS profile and most report daily use (Leiws, Laufman, \& Christakis, 2008; Buffardi \& Campbell, 2008; Ross et al., 2009). SNSs allow students to create a personal web profile, communicate with online friends and build an online social network (Ellison, Steinfield, \& Lampe, 2007; Boyd, 2007). Previous work has demonstrated that between a quarter and a third of college students display references which are consistent with symptoms of clinical depression on SNSs (A Pilot Evaluation of Associations Between Displayed Depression References on Facebook and Self-reported Depression Using a Clinical Scale, 2011; Feeling bad on Facebook: depression disclosures by college students on a social networking site, 2011). In a previous pilot study, displayed depression symptom references were associated with self-reported depression symptoms among college students (A Pilot Evaluation of Associations Between Displayed Depression References on Facebook and Self-reported Depression Using a Clinical Scale, 2011; Feeling bad on Facebook: 
depression disclosures by college students on a social networking site, 2011). However, the views of college students on what these displayed depression symptoms mean to the profile owner as well as peer viewers of that profile are not known. It is possible that these associations between Facebook and selfreported depression symptoms may be more salient among freshmen, a population that may present increased risks and opportunities for intervention. Thus, the objectives of this mixed methods study were twofold. The first goal was to examine the association between Displayed Depression symptoms and clinical depression screening scores within a population of freshmen undergraduates. The second goal was to explore these participants' views regarding displayed depression references on Facebook.

\section{Methods}

This study was conducted between November 1, 2009 and February 3, 2012 and received university IRB approval.

\section{Setting and Subjects}

This study was conducted using the SNS Facebook (www.Facebook.com). This SNS was selected as it is the most popular SNS among the target population of college students (Buffardi \& Campbell, 2008; Google, 2010). Publicly available Facebook profiles of freshmen undergraduate students within one large state university Facebook network were investigated. To be included in the study, profile owners were required to self-report their age as 18 to 19 years old and provide evidence of Facebook profile activity in the last 30 days.

\section{Data Collection and Recruitment}

The Facebook search engine was used to search for profiles within the selected university's network among the freshmen undergraduate class. At the time of this study, Facebook provided search results in lists of up to 500 profiles, not all of which met search criteria. A single search was conducted using the Facebook search engine and all profiles within those results were assessed for eligibility. The majority of ineligible profiles were due to privacy settings $(\mathrm{N}=293)$, incomplete demographic information $(\mathrm{N}=93)$ or were graduate students' profiles $(\mathrm{N}=27)$. A total of 188 freshmen student profiles were eligible for evaluation.

All eligible profiles were evaluated by three trained coders using a research codebook. This codebook has been used in previous work evaluating displayed depression references on SNS profiles (A Pilot Evaluation of Associations Between Displayed Depression References on Facebook and Self-reported Depression Using a Clinical Scale, 2011; Kim et al., 2010). The coders viewed one year of status updates in order to determine whether references to depression symptoms were present, starting from the date of profile evaluation and going back to the same date one year prior. For profiles that met inclusion criteria, profile owners were called at their listed phone number. After verifying identity, the study was explained and profile owners were invited to participate in an interview.

\section{Interview Procedures}

Interviews were conducted one-on-one with a trained graduate student. After explaining the study and obtaining consent, the interviewer provided the participant access to an online survey. After survey completion, the interviewer asked the participant a series of open-ended questions that were audio recorded. Respondents who completed the interview were provided a $\$ 50$ incentive.

\section{Data Sources and Variables}

\section{Facebook Profiles}

From each SNS profile that met inclusion criteria, demographic data and displayed depression symptom reference data were recorded, including verbatim text from profiles. If present, identifiable information was removed from text references. References to depression symptoms were defined using the DSMIV symptom criteria for a major depressive episode (MDE) (Association, A.P, 2000). The criteria for MDE included depressed mood, loss of interest/pleasure in activities, appetite changes, sleep problems, psychomotor agitation or retardation, energy loss, feeling worthless or guilty, decreased concentration or suicidal ideation (Association, A.P, 2000). Status updates were considered a depression symptom reference if they fit one of the described depression criteria by keyword or a synonym. For example, one symptom keyword of major depression is "hopeless," therefore a status update stating "I feel hopeless" would be coded as a reference to depression. The term "giving up" is a synonym of "hopeless," therefore, a status update disclosing "I feel like giving up" would be coded as a reference to depression. Status updates that clearly referenced a person other than the profile owner (i.e. "Matt is sitting next to me in class and he looks sad"), or references to the common situational experience of having a bad day (i.e. “I’m having a bummer of a day”) were not considered depression references.

Profiles were categorized into one of two groups. Profiles with one or more references to depression symptoms were considered "Depression Displayers." Profiles without any depression symptom references were considered "Non-Displayers." A $20 \%$ random subsample of profiles was evaluated by all three coders to test interrater reliability. Fleiss' Kappa statistic was used to evaluate the extent to which there was overall agreement in the coding of the presence or absence of depression references on a profile, as well as overall agreement among coders for the categorization of the depression references. Fleiss' kappa was 0.79 for the presence or absence of depression references present on profiles.

\section{Interviews}

Participants completed an online version of the Patient Health Questionnaire (PHQ-9) clinical screen for depression. This screen is based on Diagnostic and Statistical Manual of Depressive Disorders version four (DSM-IV) criteria for a MDE and has been validated in both adult and adolescent populations (Vance, Howe \& Dellavalle, 2009; Peppard, Austin \&Brown 2007). The PHQ-9 scale inquires about frequency of depression symptoms experienced in the last two weeks, such as depressed mood and hopelessness. Response categories include: not at all, several days, nearly half the days, and nearly every day. PHQ-9 scores range from 0 to 27; a score of less than 5 suggests no depression, a score of 5 or greater suggests depression. Depression diagnostic categories within the PHQ-9 are differentiated as follows: a total score of 5 - 9 suggests mild depression; a score of 10 - 14 suggests moderate depression and over 15 suggests moderately severe depression. 
Participants were then asked the following open-ended questions: "In some of our research studies, we've found that many college students display references to depression on Face-book. What do you think those references mean? What do you think might motivate a college student to display a reference to mental health on their Facebook profile? Do you think there are differences in how females display these references compared to males?”

\section{Analysis}

Categorical outcome measures were summarized as frequencies and percentages. Outcome variables measured on a continuous scale were summarized in terms of means, standard deviations, medians and ranges. Chi-square tests were used to evaluate Depression Displayers and Non-Displayers and the association with categorical demographic variables. The nonparametric Wilcoxon Rank Sum test was used to compare the PHQ-9 total scores between various subgroups.

The association between displayed depression symptom references on Facebook and depression measured by the PHQ-9 was evaluated in three steps. First, the PHQ-9 total scores were dichotomized into a no risk for depression category (total score $<5$ ) and an "at risk" for depression category (total score five or greater). A chi-square test was used to compare the proportions of participants at risk for depression between Non-Displayers and Depression Displayers. Second, the association between displayed depression symptom references on Facebook and all four PHQ-9 depression categories (none, mild depression, moderate depression, moderately severe depression) was evaluated using the Cochran-Armitage trend test. In the final step, we evaluated whether being a Depression Displayer was an independent predictor for any PHQ-9 depression category using multivariate logistic regression. Demographic variables and two-way interaction terms between categorical variables were included as covariates in the initial non-parsimonious model. Backward selection was used to identify a final parsimonious model. Data analyses were conducted using SAS software version 9.2 (SAS Institute, Cary, NC). All $P$ values were 2 -sided, and $P<0.05$ was used to indicate statistical significance.

Qualitative analysis of interview data was conducted in an iterative approach (Creswell, 1998). Three investigators individually evaluated transcripts to develop preliminary themes and representative quotations. These reviewers then met to discuss themes using the Constant Comparative method (Glasser \& Strauss, 2011). The group discussed until consensus on themes was reached and representative quotations were selected.

\section{Results}

A total of 132 participants completed the interview (70\% response rate). Participants had an average age of 18.4 years (SD 0.49 ) and included 64 males (48.5\%). Table 1 summarizes demographic data.

\section{Displayed Depression on Facebook}

Among Facebook profiles, 33.6\% displayed references to one or more depression symptoms (Depression Displayers) and $66.4 \%$ had no depression symptom references displayed on the profile (Non-Displayers). The mean number of references to depression symptoms per profile was $1.2(\mathrm{SD}=2.1)$, while the
Table 1.

Participant demographic information $(\mathrm{N}=132)$.

\begin{tabular}{cc}
\hline Gender & Number (\%) \\
Male & $64(48.5 \%)$ \\
Female & $68(51.2 \%)$ \\
Age (years) & \\
18 & $75(56.8 \%)$ \\
19 & $57(43.2 \%)$ \\
Ethnicity & \\
Caucasian & $120(91.6 \%)$ \\
Asian American & $5(2.8 \%)$ \\
African American & $1(0.8 \%)$ \\
Hispanic/Latino & $1(0.8 \%)$ \\
Mixed/Other & $4(3.2 \%)$ \\
Missing & $1(0.8 \%)$ \\
Facebook Depression Display Category & \\
Non-Displayer & $88(66.4 \%)$ \\
Depression Displayer & $44(33.6 \%)$ \\
PHQ-9 Depression Category & \\
None & $81(61.4 \%)$ \\
Mild & $40(30.3 \%)$ \\
Moderate & $9(6.8 \%)$ \\
Moderately Severe & $2(1.5 \%)$ \\
\hline
\end{tabular}

median number of references was 0 with a range of 0 to 11 references.

Females were more likely to be Depression Displayers (41\% Displayers) compared to males (24\% Displayers) $(p=0.02)$. Among females who were Depression Displayers, the mean number of depression displays was 2 (SD 1.62), the median was 1 and the range was 1 to 7 . Among males who were Depression Displayers, the mean number of depression symptom displays was 3.2 (SD 3.2), the median was 2 and the range was 1 to 11 . Thus males were less likely to display references to depression symptoms, but among those who displayed such depression references they did so more frequently compared to females $(p=0.003)$. Though there were few non-white participants, they were also more likely to display depression symptom references compared to white participants $(p=0.009)$, though there were not statistically significant differences in frequency of display. See Table 2.

\section{Displayed Depression on Facebook}

Among Facebook profiles, 33.6\% displayed references to one or more depression symptoms (Depression Displayers) and $66.4 \%$ had no depression symptom references displayed on the profile (Non-Displayers). The mean number of references to depression symptoms per profile was $1.2(\mathrm{SD}=2.1)$, while the median number of references was 0 with a range of 0 to 11 references.

Females were more likely to be Depression Displayers (41\% Displayers) compared to males (24\% Displayers) $(p=0.02)$. Among females who were Depression Displayers, the mean number of depression displays was $2(\mathrm{SD}=1.62)$, the median was 1 and the range was 1 to 7 . Among males who were Depression Displayers, the mean number of depression symptom displays was 3.2 (SD 3.2), the median was 2 and the range was 1 to 11 . Thus males were less likely to display references to 
Table 2.

Descriptive information for gender and race by facebook depression display category and phq-9 depression screening results.

\begin{tabular}{|c|c|c|c|c|c|c|c|}
\hline & & $\begin{array}{c}\text { Facebook } \\
\text { Non-Displayers }\end{array}$ & $\begin{array}{l}\text { Facebook } \\
\text { Depression } \\
\text { Displayer }\end{array}$ & & $\begin{array}{l}\text { PHQ-9 Score Indicates } \\
\text { No Depression }\end{array}$ & $\begin{array}{c}\text { PHQ-9 Score } \\
\text { Indicates Depression }\end{array}$ & \\
\hline Variable & Value & N (\%) & N (\%) & P Value $^{1}$ & & & P Value $^{1}$ \\
\hline \multirow{2}{*}{ Gender } & Female $(\mathrm{N}=68)$ & 38 (44.2\%) & 30 (66.7\%) & \multirow{2}{*}{0.02} & 39 (57.4\%) & 29 (42.6\%) & 0.37 \\
\hline & Male $(\mathrm{N}=63)$ & 48 (55.8\%) & 15 (33.3\%) & & 42 (66.7\%) & 22 (34.9\%) & \\
\hline \multirow{2}{*}{ Race } & White (N = 119) & 82 (96.5\%) & 37 (82.2\%) & \multirow{2}{*}{0.01} & 75 (63\%) & 45 (37.8\%) & 0.22 \\
\hline & Non-White $(\mathrm{N}=11)$ & $3(3.5 \%)$ & $8(17.8 \%)$ & & $6(54.5 \%)$ & $6(54.5 \%)$ & \\
\hline
\end{tabular}

${ }^{1}$ Fisher's exact Test.

depression symptoms, but among those who displayed such depression references they did so more frequently compared to females $(p=0.003)$. Though there were few non-white participants, they were also more likely to display depression symptom references compared to white participants $(p=0.009)$, though there were not statistically significant differences in frequency of display. See Table 2.

\section{PHQ-9 Scores}

The mean PHQ-9 total score was 4.1 (SD = 3.3) and the median was 3 (range 0 to 16). A total of 81 participants had total scores which indicated no risk for depression (61.4\%). Table 2 illustrates the proportion of participants who met each of the depression criteria on the PHQ-9. Among participants whose total scores indicated depression, 40 participants met criteria for mild depression (30.3\%), 9 participants met criteria for moderate depression (6.8\%) and 2 participants met criteria for moderately severe depression (1.5\%). The mean PHQ-9 score for females was $4.5(\mathrm{SD}=3.7)$ compared to $3.5(\mathrm{SD}=2.7)$ for males $(p=0.07)$.

\section{Association between Facebook Display and PHQ-9 Scores}

The PHQ-9 score was significantly higher among Depression Displayers when compared to Non-Displayers. The median total PHQ-9 score for Depression Displayers was 5 (range 0 to $15)$, compared to a median total score of 3 for Non-Displayers (range 0 to 16$)(p=0.04)$.

Our initial analytic approach examined the relationship between PHQ-9 scores that indicated any category of depression (PHQ-9 total score $>4$ ) compared to no risk for depression. We found that among Depression Displayers, 51.1\% had PHQ-9 scores that met criteria for Depression compared to $32.6 \%$ of Non-Displayers $(p=0.04)$.

Our second analysis examined the relationship between displayed depression references on Facebook and all four depression categories (None, Mild, Moderate, Moderately severe). A significant negative trend was detected for the proportions of Depression Displayers across the depression categories. ( $p=$ 0.033.) Specifically, the proportions of Depression Displayers were $48.9 \%$ (None), 37.8\% (Mild), $11.1 \%$ (Moderate), and 2.2\% (Moderately severe). Table 3 illustrates these findings.

Our third approach was to conduct a multivariate analysis in order to evaluate whether depression reference display on Facebook was an independent predictor for a total PHQ-9 score indicating depression. Gender, ethnicity (white vs. non-white), number of Facebook friends and two-way interaction terms
Table 3.

Association between Facebook displayed depression category and PHQ-9 depression category.

\begin{tabular}{ccccc}
\hline & & Non-Displayers & $\begin{array}{c}\text { Depression } \\
\text { Displayers }\end{array}$ & $\begin{array}{c}\text { P } \\
\text { Value }\end{array}$ \\
\cline { 3 - 5 } & & N (\%) & N (\%) & \\
\hline $\begin{array}{c}\text { Depression } \\
\text { Risk by PHQ-9 } \\
\text { Score }\end{array}$ & No Risk & $58(67.4 \%)$ & $22(48.9 \%)$ & $0.04^{1}$ \\
& At Risk & $28(32.6 \%)$ & $23(51.1 \%)$ & \\
$\begin{array}{c}\text { Depression } \\
\text { Category by } \\
\text { PHQ-9 Score }\end{array}$ & None & $58(67.4 \%)$ & $22(48.9 \%)$ & \\
& Moderate & $4(4.7 \%)$ & $5(11.1 \%)$ & $0.03^{2}$ \\
& Moderately & $1(1.2 \%)$ & $1(2.2 \%)$ & \\
\hline
\end{tabular}

${ }^{1}$ Chi-square test. ${ }^{2}$ Cochran-armitage trend test.

were included as covariates in the initial non-parsimonious model. Backward selection with a 0.1 significance level for removing effects was used to identify a parsimonious model. Depression reference display was identified as an independent predictor for PHQ-9 depression in the multivariate analysis. Specifically, participants who displayed Depression references on Facebook were twice as likely (OR 2.1, 95\% CI: 1.01 - 4.5, $p=0.04$ ) to score into one of the depression categories on the PHQ-9.

A marginally significant interaction between depression reference display and gender was detected in the multivariate analysis $(p=0.08)$. Hence, subgroup analyses were conducted for males and females separately. Among females, the odds ratio for PHQ-9 depression was 3.7 (95\% CI: 1.4 - 10.1) when comparing Depression Displayers to Non-Displayers. There was no significant association between depression reference display and PHQ-9 depression among males.

\section{Interview}

Qualitative analysis of transcripts revealed several consistent findings across interviews. First, participants described several perceived meanings behind displayed depression symptoms. These meanings mostly centered on displaying depression references as a way to express feelings or seek support. Some participants described their perception that depression displays represent a cry for help:

"I feel that that's like a cry for help, like they want people to see it and they want people to ask about it and they want people to like comfort them in some way." (Female, Displayer).

Another commonly described motivation for depression displays was to seek feedback, empathy or support: 
"I think that at the moment in time they posted it, they were feeling incredibly depressed and were trying to use the internet to take a poll and see if anyone else is feeling that way. Then people can comment." (Female, Non-Displayer).

A final commonly described motivation was to relieve stress or vent feelings: "when they're stressed out, or sometimes you're just tense, like you have homework, you have work to do, like work, you might be sick, and just everything's going wrong. You need a break and you feel like you're ready to explode." (Female, Displayer).

While some variety exists in these perceived meanings for depression disclosures, all related to a core motivation of trying to feel better. Participants also discussed the importance of the pattern of display, that displays are more common around stressful times such as exams or relationship breakups. Participants also commented that a pattern of depression symptoms displays was more meaningful compared to a single disclosure:

"Um, I would say some people kind of do it for attention. They'll put something like 'school is so frustrating and so depressing' because people will comfort them. I may have done that, I definitely put up something about how school is really hard and I couldn't handle it and that kind of thing. And then my friends are like, 'it's ok, it'll get better, you can do it,' and it's kind of a self-confidence boost. But unless there's, like if I see status updates, unless there's a lot of depressing ones in a row, I'm not too worried about those people" (Female, Displayer).

These common meanings were discussed by both Depression Displayers and Non-Displayers. However, there were subtle differences noted in how some Non-Displayers described their perception of displayed depression references. Non-Displayers were more likely to describe the feeling that the displayed depression symptoms were motivated by a desire for attention:

"maybe it's for attention, or to have someone help them figure out what's going on, or even to relieve stress, sometimes just saying something is a way or relieving it, and you're relieving it to a lot of people which may be helping." (Female, Non-Displayer).

Some Non-Displayers went as far as to criticize the practice of displaying depression symptoms on Facebook:

“Um, I don't know, sometimes I've seen people that are emotional or post status updates and I just don't think that's really the right place to put it. You should actually talk to someone about your mental health, you shouldn't be like posting it on Facebook, you should be talking to your friends or a professional, not using a status update or bumper sticker." (Female, Non-Displayer).

Non-Displayers also mentioned not being sure whether the displayed depression symptom was meant as a joke:

"I think sometimes it could be seen as a joke, and other times they could actually be true and it's someone's way of asking for the attention that they want." (Female, Non-Displayer).

"Yeah, probably just exaggerated, um, not like serious. If some kid had some mental health problem, I don't think they'd post it there." (Male, Non-Displayer).

Interviews also elicited feedback from participants regarding whether gender differences were present among displayed depression symptoms on Facebook. Many participants described differences in social or gender norms and expectations for publicly displaying emotions or feelings. Representative quotes from gender differences are in Table 4.
Table 4.

Gender differences in display of depression symptoms on facebook.

"I think girls are more likely to [display depression symptoms]. I feel like I don't really see that thing with boys. It's more common with girls, I think maybe more acceptable I guess. Whatever stereotypes go with it." (Female, Displayer).

"Um, well, I think girls are more open to what they're feeling and guys just want to be seen as like they're more laid back and they have things under control and are not stressed are. So I think girls are just more willing to share their feelings." (Female, Non-Displayer).

"Yeah, I feel like females are more open about it and basically what I've learned it tends to be more, mental health things, I mean they tend to be "Oh I'm sad because of..." or they do a song lyric or something, where guys for the most part guys don't really post a lot of things involving emotions. Again that is kind of like the social norms playing like part or also just physiology.” (Male, Displayer).

\section{Gender differences in how Facebook itself is used}

\begin{abstract}
"Um yeah, I don't know um certain the girls I know tend to be more emotional than guys I know. And it comes out more, especially because that my girlfriends are much more active on Facebook so I see it much more from them." (Male, Displayer).

"It seems like guys are less likely to call out for things like that, try to get attention on Facebook, and a lot of girls are. But at the same time girls seem like just make more status updates in general, about the good things and the bad. Guys make less comment in general and when they do they're less attached to a personal issue." (Male, Non-Displayer). "I don't think there are that many differences, I think guys generally don't get a response to what they display on a Facebook page. Girls do, and they get it from girls. Girls are the ones who really go on Facebook and browse around for a long time. I don't know, I think the reason is all the same, anything you do over Facebook you're wanting to get attention, that's just my opinion (Female, Displayer).
\end{abstract}

\section{Discussion}

This study presents findings from both quantitative and qualitative data to explore displayed depression symptom references on Facebook. Findings suggest a positive association between displayed depression symptoms on Facebook and selfreported depression symptoms using a clinical screen among freshmen undergraduates. Freshmen generally viewed diplayed depression references as a way to seek support or attention; however, Non-Displayers more often described feelings of negativity or attention-seeking associated with these references.

The finding that approximately a third of college students referenced depression symptoms on Facebook is consistent with previous work (Feeling bad on Facebook, 2011; A Pilot Evaluation of Associations Between Displayed Depression References on Facebook and Self-reported Depression Using a Clinical Scale, 2011). Similarly, the majority of Depression Displayers had clinical scores in the mild depression category (A Pilot Evaluation of Associations between Displayed Depression References on Facebook and Self-reported Depression Using a Clinical Scale, 2011). However, the current findings focus on freshmen college students and found a heightened association between Facebook displayed depression symptoms and depression identified by a clinical screen, with Depression Displayers over twice as likely to be at risk for depression. Freshmen also represent a group at risk for depression and less likely to be proactive in seeking care for depression (Cutrona, 1982).

Placing these findings in the context of related work, Wei, Russell and Zakalik (2005). investigated the role of emotional disclosures among college students. Their study found that 
among freshmen students, emotional self-disclosure was a mediator to decrease mild depression. However, emotional comfort with self-disclosure did not play a role as a mediator when more severe depression was present. This work provides insights to the current findings in two ways. First, Facebook depression symptom references may represent an innovative form of emotional self-disclosure. Students who choose to disclose depression symptoms, even via Facebook, may experience an emotional benefit from their actions. It is worth considering whether displaying depression symptoms on Facebook and receiving social support may allow an adolescent with depression to maintain a symptom level in the "mild" category during times of stress when that adolescent is at risk for heightened symptoms. Second, findings suggest that the association between Facebook displayed depression references and self-reported depression symptoms is most clearly seen among those with mild depression symptoms. It is possible that students with more severe depression do not benefit from, and thus are less likely to engage in, displayed depression disclosures.

If it is the case that displayed depression references on Facebook represent college students who may have mild depression, and if these Facebook disclosures represent emotional selfdisclosure and support-seeking, then it is worth considering how to support or improve what is currently taking place in this naturalistic environment. One consideration is to provide education to college students (the majority of whom are Non-Displayers) regarding the positive association between Facebook displayed depression references and likelihood of depression. Colleges could consider awareness campaigns to provide students information that depression references may represent mild depression, and education about resources available to students. As both peer support interventions and online support interventions have been found to be effective in treating depression, educating students about how to respond to peers' displayed depression symptom references may have a meaningful impact (Pfieffer et al., 2011; Houston, Cooper, \& Ford, 2002). Given the high prevalence of depression in this population, and the low frequency of help-seeking behavior, it is exciting to consider Facebook depression disclosures as a potential means for impacting mild depression.

Similar to previous work, females were more likely to be Depression Displayers as well as to score into a depression category of the PHQ-9 (Feeling bad on Facebook, 2011; A Pilot Evaluation of Associations Between Displayed Depression References on Facebook and Self-reported Depression Using a Clinical Scale, 2011) The association between displayed depression references and PHQ-9 reported depression was strong among females, suggesting this may be an ideal group to target for future interventions using Facebook. Findings regarding males are less clear. While males were less likely to display depression references, male Depression Displayers displayed as frequently or more frequently compared to female Displayers. Qualitative findings provide insights that depression displays by males were considered less socially appropriate by peers and more likely to be viewed as a joke. It is possible that males who display depression references are less likely to receive supportive comments or feedback, though this may be the purpose of their disclosure. Future studies among male college students who display depression references on SNSs may yield further insights into the meaning of these references and the pattern of their display, as well as possible opportunities for targeting interventions to this subgroup.
Study findings are limited in that we only examined publicly available profiles on one SNS. Therefore we cannot generalize our findings to profiles that were set to private, or to profiles on other SNSs. This study took place during a transition time for Facebook, profile security settings were trending towards increased security settings. Thus, many of the profiles we screened for eligibility were excluded due to privacy settings. In the present time, this study method would be unlikely to succeed given that private security settings are now the norm. It is important to note that SNS profile privacy settings are not permanent; profile owners may change their privacy settings at any time or to reflect what security upgrades are offered by Facebook. It is unclear whether profile owners who maintained a private profile at the time of this study would be more likely, or less likely, to display depression references. Further, generalization to other universities or upperclassmen is not warranted. Finally, among older adolescents who have been diagnosed with depression, their Facebook usage patterns are not well understood.

Despite these limitations, our study represents a unique portrait of displayed depression symptoms on Facebook during a time in which Facebook security settings frequently allowed public glimpses of their content. In the present time, security settings have changed, leading to an increased likelihood that profiles are private. However, today's college students are also likely to friend adults in their lives, such as parents or college professors. Thus, while these profiles may not be publicly available, they may be accessible by caring adults who may see displayed depression references and wonder what they mean. Our study findings demonstrate that displayed depression symptoms on Facebook likely have meaning to those who choose to display them.

There are several ways in which these findings could be used to enhance screening or intervention efforts towards reducing depression among college students. Attention to both privacy concerns and ethics are paramount to the success of any future research or clinical efforts involving SNSs (Correa, Hinsley, \& de Zuniga, 2010; Moreno, Fost \& Christakis, 2008). A first option is considering raising awareness of the common meanings and motivations for displayed depression symptoms on Facebook among incoming college students. This may allow students who are Non-Displayers to recognize if a peer is using Facebook to seek support or in need of resources. A second option is to consider targeted messaging based on the displayed content on a SNS profile. Advertisements on Facebook are triggered by keywords displayed on the profile and can be tailored to depression keywords. It is possible that universities could choose to place messages or educational materials, such as a link to the university health services, targeted to keywords regarding depression symptoms such as “depression” or "hopeless.” Future study should evaluate how these options could enhance and complement current screening efforts on college campuses.

\section{REFERENCES}

Association, A.C.H. (2009). American college health association: National college health assessment II: Reference group data report fall 2008. Baltimore: American College Health Association.

Association, A.C.H. (2010). National college health assessment. Association, A. P. (2000). Diagnostic and statistical manual of mental disorders. Washington DC: American Psychiatric Association. 
Boyd, D. (2007). Why youth (heart) social networking sites: The role of networked publics in teenage social life. In D. Buckingham, Ed., MacArthur Foundation Series on Digital Learning: Youth, Identity and Media Volume (pp. 119-142). Cambridge, MA: MIT Press.

Buffardi, L. E., \& Campbell, W. K. (2008). Narcissism and social networking Web sites. Personality and Social Psychology Bulletin, 34, 1303-1314. doi:10.1177/0146167208320061

Compas, B. E., et al. (1986). A prospective study of life events, social support, and psychological symptomatology during the transition from high school to college. American Journal of Community Psychology, 14, 241-257. doi:10.1007/BF00911173

Correa, T., Hinsley, A. W., \& de Zuniga, H. G. Who interacts on the Web? The intersection of users' personality and social media use. Computers in Human Behavior, 26, 247-253. doi:10.1016/j.chb.2009.09.003

Creswell, J. W. (1998). Qualitative inquiry and research design: Choosing among five traditions. Thousand Oaks, CA: Sage.

Cutrona, C. E. (1982). Transition to college: Loneliness and the process of social adjustment. In L. A. Peplau, \& D. Pearlman, Eds., Loneliness: A sourcebook of current theory, research and practice (pp. 291-309). New York: Wiley Interscience.

Deas, D., \& Brown, E. S. (2006). Adolescent substance abuse and psychiatric comorbidities. Journal of Clinical Psychiatry, 67, e02. doi:10.4088/JCP.0706e02

Eisenberg, D., Golberstein, E., \& Gollust, S. E. (2007). Help-seeking and access to mental health care in a university student population. Medical Care, 45, 594-601. doi:10.1097/MLR.0b013e31803bb4c1

Eisenberg, D., et al. (2009). Stigma and help seeking for mental health among college students. Medical Care Research and Reviews, 66, 522-541. doi:10.1177/1077558709335173

Ellison, N. B., Steinfield, C., \& Lampe, C. (2007). The benefits of Facebook "Friends:" Social capitol and college students' use of online social network sites. Journal of Computer-Mediated Communication, 12, 1143-1168. doi:10.1111/j.1083-6101.2007.00367.x

Garlow, S. J., et al. (2008). Depression, desperation, and suicidal ideation in college students: Results from the American Foundation for Suicide Prevention College Screening Project at Emory University. Depression and Anxiety, 25, 482-488. doi:10.1002/da.20321

Glaser, B. G., \& Strauss, A. (1967). The discovery of grounded theory: Strategies for qualitative research. Hawthorne, NY: Aldine Transaction.

Google (2010). Google Ad Planner.

https://www.google.com/adplanner/planning/site_details\#siteDetails? identifier=facebook.com\&geo=US\&trait_type $=1 \&$ lp $=$ false

Houston, T. K., Cooper, L. A., \& Ford, D. E. (2002). Internet support groups for depression: A 1-year prospective cohort study. American Journal of Psychiatry, 159, 2062-2068. doi:10.1176/appi.ajp.159.12.2062

Hunt, J., \& Eisenberg, D. (2010). Mental health problems and helpseeking behavior among college students. Journal of Adolescent Health, 46, 3-10. doi:10.1016/j.jadohealth.2009.08.008

Kessler, R. C., et al. (1995). Social consequences of psychiatric disorders I: Educational attainment. The American Journal of Psychiatry, 152, 1026-1032.
Kim, J. H., et al. (2010). Brief report: Predictors of heavy Internet use and associations with health-promoting and health risk behaviors among Hong Kong university students. Journal of Adolescence, 33, 215-220. doi:10.1016/j.adolescence.2009.03.012

Lewis, K., Kaufman, J., \& Christakis, N. (2008). The taste for privacy: An analysis of college student privacy settings in an online social network. Journal of Computer-Mediated Communication, 14, 79. doi:10.1111/j.1083-6101.2008.01432.x

Moreno, M. A., et al. (2011). A pilot evaluation of associations between displayed depression references on facebook and self-reported depression using a clinical scale. Journal of Behavior Health Service Research.

Moreno, M. A., et al. (2011). Feeling bad on Facebook: Depression disclosures by college students on a social networking site. Depress Anxiety, 28, 447-455. doi:10.1002/da.20805

Moreno, M. A., Fost, N. C., \& Christakis, D. A. (2008). Research ethics in the MySpace era. Pediatrics, 121, 157-161. doi:10.1542/peds.2007-3015

Peppard, P. E., Austin, D., \& Brown, R. L. (2007). Association of alcohol consumption and sleep disordered breathing in men and women. Journal of Clinical Sleep Medicine, 3, 265-270.

Perry, R. P., Hall, N. C., \& Ruthig, J. C. (2007). Perceived (academic) control and scholastic attainment in higher education. In R. P. Perry, \& J. C. Smart, Eds., Scholarship of Teaching and Learning in Higher Education: An Evidence-Based Perspective (pp. 477-551). Dordrecht: Springer. doi:10.1007/1-4020-5742-3_12

Pfeiffer, P. N., et al. (2011). Efficacy of peer support interventions for depression: A meta-analysis. Gen Hosp Psychiatry, 33, 29-36. doi:10.1016/j.genhosppsych.2010.10.002

Rao, U., \& Chen, L. A. (2009). Characteristics, correlates, and outcomes of childhood and adolescent depressive disorders. Dialogues Clinical Neuroscience, 11, 45-62.

Rao, U. (2006). Links between depression and substance abuse in adolescents: Neurobiological mechanisms. American Journal of Preventive Medicine, 31, S161-S174. doi:10.1016/j.amepre.2006.07.002

Ross, C., et al. (2009). Personality and motivations associated with Facebook use. Computers in Human Behavior, 25, 578-586. doi:10.1016/j.chb.2008.12.024

Statistics, N. C. E. (2010). Digest of education statistics: 2009. Washington DC: US Department of Eduction, National Center for Education Statistics.

Vance, K., Howe, W., \& Dellavalle, R. P. (2009). Social internet sites as a source of public health information. Dermatologic Clinics, 27, 133. doi:10.1016/j.det.2008.11.010

Wei, M. F., Russell, D. W., \& Zakalik, R. A. (2005). Adult attachment, social self-efficacy, self-disclosure, loneliness, and subsequent depression for freshman college students: A longitudinal study. Journal of Counseling Psychology, 52, 602-614. doi:10.1037/0022-0167.52.4.602

Zivin, K., et al. (2009). Persistence of mental health problems and needs in a college student population. Journal of Affective Disorders, 117, 180-185. doi:10.1016/j.jad.2009.01.001 